\title{
Role of Ki-67, MRE11, and PD-L1 as Predictive Biomarkers for Recurrence Pattern in Muscle-invasive Bladder Cancer
}

\author{
CROIX C. FOSSUM ${ }^{1}$, YIN XIONG ${ }^{2}$, ANTHONY MAGLIOCCO ${ }^{2}$, SIAMAK DANESHMAND ${ }^{3}$, \\ MANJU ARON ${ }^{4}$, KENT W. MOUW ${ }^{5}$, ZARKO MANOJLOVIC ${ }^{6}$, SUSAN MCCARTHY ${ }^{2}$, \\ CHRISTINA PHUONG ${ }^{7}$, TANYA DORFF ${ }^{8}$, SUMEET K. BHANVADIA $^{4}$ and LESLIE K. BALLAS ${ }^{1}$ \\ ${ }^{1}$ Department of Radiation Oncology, Keck School of Medicine of USC, Los Angeles, CA, U.S.A.; \\ ${ }^{2}$ Department of Pathology, Moffitt Cancer Center and Research Institute, Tampa, FL, U.S.A.; \\ ${ }^{3}$ Department of Urology, Keck School of Medicine of USC, Los Angeles, CA, U.S.A.; \\ ${ }^{4}$ Department of Pathology, Keck School of Medicine of USC, Los Angeles, CA, U.S.A.; \\ ${ }^{5}$ Department of Radiation Oncology, Dana-Farber Cancer Institute/Brigham \& Women's Hospital, \\ Harvard Medical School, Boston, MA, U.S.A.; \\ ${ }^{6}$ Department of Translational Genomics, Keck School of Medicine of USC, Los Angeles, CA, U.S.A.; \\ ${ }^{7}$ Department of Radiation Oncology, University of California - San Francisco, San Francisco, CA, U.S.A.; \\ ${ }^{8}$ Department of Medical Oncology, City of Hope, Duarte, CA, U.S.A.
}

\begin{abstract}
Background/Aim: Muscle invasive bladder cancer $(M I B C)$ is an aggressive disease with high rates of local recurrence following radical cystectomy $(R C)$. Currently, there are no clinically validated biomarkers to predict local only recurrence $(L O R)$ and guide adjuvant treatment decisions. This pilot study evaluated the role of Ki-67, MRE11 and PD$L 1$ as predictive biomarkers for recurrence patterns in patients undergoing RC for MIBC. Patients and Methods: Our institutional cystectomy database containing cases from 19922014 was queried for patients with local only recurrence $(L O R)$, and case-matched to patients with distant recurrence $(D R)$ and no recurrence (NR). Clinicopathological data were collected and a tissue microarray was analyzed for presence of Ki-67, MRE11, and PD-L1 using immunofluorescence and immunohistochemistry. Results: Pathologic specimens from 42 patients (18 NR, $16 \mathrm{LOR}$, and $8 \mathrm{DR}$ ) were reviewed. Compared to normal bladder tissue, tumors had increased expression of Ki-67 $(p<0.01)$ and PD-L1 $(p<0.05)$. High Ki67 was associated with recurrence pattern (local vs. distant) on univariate analysis $(p<0.05)$. Ki-67 cell density varied by
\end{abstract}

This article is freely accessible online.

Correspondence to: Croix C. Fossum, MD, USC Norris Cancer Hospital, Department of Radiation Oncology, 1441 Eastlake Avenue, Los Angeles, CA 90033-0804, U.S.A. Tel: +1 3238653050 , e-mail: Fossum.croix@gmail.com

Key Words: Biomarkers, muscle invasive bladder cancer (MIBC), local recurrence, cystectomy. recurrence type: LOR (1354 cells/ $\left.\mathrm{mm}^{2}\right), D R\left(557\right.$ cells $\left./ \mathrm{mm}^{2}\right)$ and NR $\left(1111\right.$ cells $\left./ \mathrm{mm}^{2}\right)(p=0.034)$. Conclusion: Our selected biomarkers could distinguish MIBC from normal bladder tissue but could not classify samples by recurrence pattern.

Muscle-invasive bladder cancer (MIBC) carries a relatively poor prognosis due to high rates of local and distant recurrence following radical cystectomy (1-2). Although it confers an overall survival advantage, neoadjuvant chemotherapy (NAC) does not decrease rates of pelvic recurrence, which can occur in $8-40 \%$ of patients with locally advanced disease (3-6). Postoperative radiation (PORT) can reduce pelvic recurrence rates, but appropriate patient selection remains controversial. Decisions regarding PORT are currently based on clinicopathologic features at the time of cystectomy.

Molecular subtypes of MIBC have been shown to better stratify outcomes compared to clinicopathologic features alone (7-10). Prior studies have utilized whole transcriptome sequencing to classify tumors into basal, luminal, and high TP53-expressing molecular subtypes, which are useful in predicting the overall risk of recurrence (local and distant) and responsiveness to chemotherapy (11-13). Specific biomarkers including MRE11, PD-L1 and Ki-67 have been shown to be prognostic and, in some cases, predictive of oncologic outcomes following definitive management of MIBC (10, 14-16). However, there are no clinically validated biomarkers to predict local recurrence and guide treatment decisions including use of PORT.

In this pilot study, we evaluated MRE11, PD-L1, and Ki-67 expression in patient tumors and normal bladder tissue using quantitative immunohistochemistry (IHC) and immunofluo- 
rescence (IF) assays and compared our findings to oncologic outcomes in our institutional cystectomy database. Our primary objective was to define a molecular signature for local recurrence to improve selection of patients for PORT.

\section{Patients and Methods}

Cystectomy database. Following IRB approval (IRB\#: HS-01B014CR015), our institutional bladder cancer database was queried for patients that experienced a local only recurrence (LOR) following cystectomy from January 1992 through December 2014. LOR was defined as radiographically detected pelvic recurrence up to the level of the common iliac vessels with no disease detected outside of the pelvis. The database was then queried to case-match the 20 LOR patients to 20 patients without recurrence (NR) and 20 patients experiencing a distant recurrence (DR), which was defined as an extra-pelvic first recurrence. The variables used to match patients were stage, type of urinary diversion, use of NAC, and the decade the operation was performed.

Pathologic review. Specimens from 42 patients (18 NR, 16 LOR, and $8 \mathrm{DR}$ ) had sufficient tissue for review. A single pathologist examined all specimens to identify appropriate areas for construction of a tissue microarray (TMA). The TMA was built from formalin-fixed, paraffin embedded (FFPE) tissue and probed using antibodies directed against MRE11 (Abcam, EPR3471), PDL1 (CST, E1L3N), and Ki-67 (Abcam, polyclonal). IF was performed for all three proteins (Figure 1) and IHC was performed for PD-L1 and Ki-67. Normal bladder tissue adjacent to each tumor $(n=42)$ from RC specimens was also included in the TMA.

Multiplex immune panel procedure. FFPE tissue samples were immunostained using the PerkinElmer OPAL TM 7-Color Automation IHC kit (Waltham, MA, USA) on the BOND RX autostainer (Leica Biosystems, Vista, CA, USA). DAPI counterstain was applied to the multiplexed slide and was removed from BOND RX for coverslipping. Autofluorescence slides (negative control) were included, which used primary and secondary antibodies omitting the OPAL fluors and DAPI. All slides were imaged with the Vectra ${ }^{\circledR}$ Automated Quantitative Pathology Imaging System (Akoya Biosciences, Marlborough, MA, USA).

Quantitative image analysis. Multi-layer TIFF images were exported from inForm (PerkinElmer) and loaded into HALO (Indica Labs, Albuquerque, NM, USA) for quantitative image analysis. The tissue was segmented into individual cells using the DAPI marker which stains cell nuclei. A positivity fluorescent threshold was determined for each biomarker based on published staining patterns and intensity for that specific antibody (17-19). After setting a positive threshold for each staining biomarker, the entire image set was analyzed with the created algorithm.

Statistics and model building. Four IHC measurements (2 per biomarker) and nine IF measurements (3 per biomarker) were recorded for a total of 13 measurements for each TMA core. IHC measurements included $\mathrm{H}$ score and Combined Positive Score (CPS) $(<10,>10)$ for PD-L1 and $\mathrm{H}$ score and percentage $(<1,>1)$ for $\mathrm{Ki}-$ 67. IF variables included absolute positive cells per TMA core, percent positive cells (number of positive cells / total number of cells
Table I. Patient characteristics.

\begin{tabular}{lc}
\hline & $\mathrm{n}(\%)$ \\
& $(\mathrm{N}=42)$ \\
\hline Age, years & $70(53-85)^{*}$ \\
Gender & \\
Male & $26(62 \%)$ \\
Female & $16(38 \%)$ \\
pT stage & \\
pT1 & $1(2 \%)$ \\
pT2 & $7(17 \%)$ \\
pT3 & $22(52 \%)$ \\
pT4 & $12(29 \%)$ \\
pN stage & \\
pN0 & $15(36 \%)$ \\
pN1 & $10(24 \%)$ \\
pN2 & $14(33 \%)$ \\
pN3 & $3(7 \%)$ \\
Margin Status & \\
Positive & $6(14 \%)$ \\
Negative & $35(83 \%)$ \\
Unknown & $1(2 \%)$ \\
Presence of LVSI & \\
Yes & $22(52 \%)$ \\
No & $17(40 \%)$ \\
Unknown & $3(7 \%)$ \\
Neoadjuvant chemo & \\
Yes & $10(24 \%)$ \\
No & $32(76 \%)$ \\
\hline
\end{tabular}

*Data shown as median (range). LVSI: Lymphovascular space invasion.

per core $\times 100$ ), and positive cell density $\left(\right.$ cells $/ \mathrm{mm}^{2}$ ) for each biomarker. Percentage and density of cells expressing the biomarkers were included to normalize the data and account for varying number of total cells in each core. $t$-Tests, univariate and multivariate logistic regressions, and Cox proportional hazard models were performed to assess the association of variables with oncologic outcomes. Principal component analyses (PCAs) were performed to separate patients by recurrence pattern using the "prcomp" function provided by R statistical software. Multidimensional scaling maps were constructed.

\section{Results}

Patient characteristics. Patient characteristics are shown in Table I. The median follow-up was 12.2 years and the median age was 70 years (range $=53-85$ ). Sixteen patients were female (38\%). A majority of patients had locoregionally advanced disease with $32(81 \%)$ having T3/T4 disease and $27(64 \%)$ with positive lymph nodes. Six patients $(14 \%)$ had positive margins and $22(52 \%)$ had lymphovascular space invasion (LVI). Ten patients $(24 \%)$ received NAC. None received radiation.

Tumor vs. normal tissue. There were notable differences between tumor and normal tissue with regard to biomarker 
a

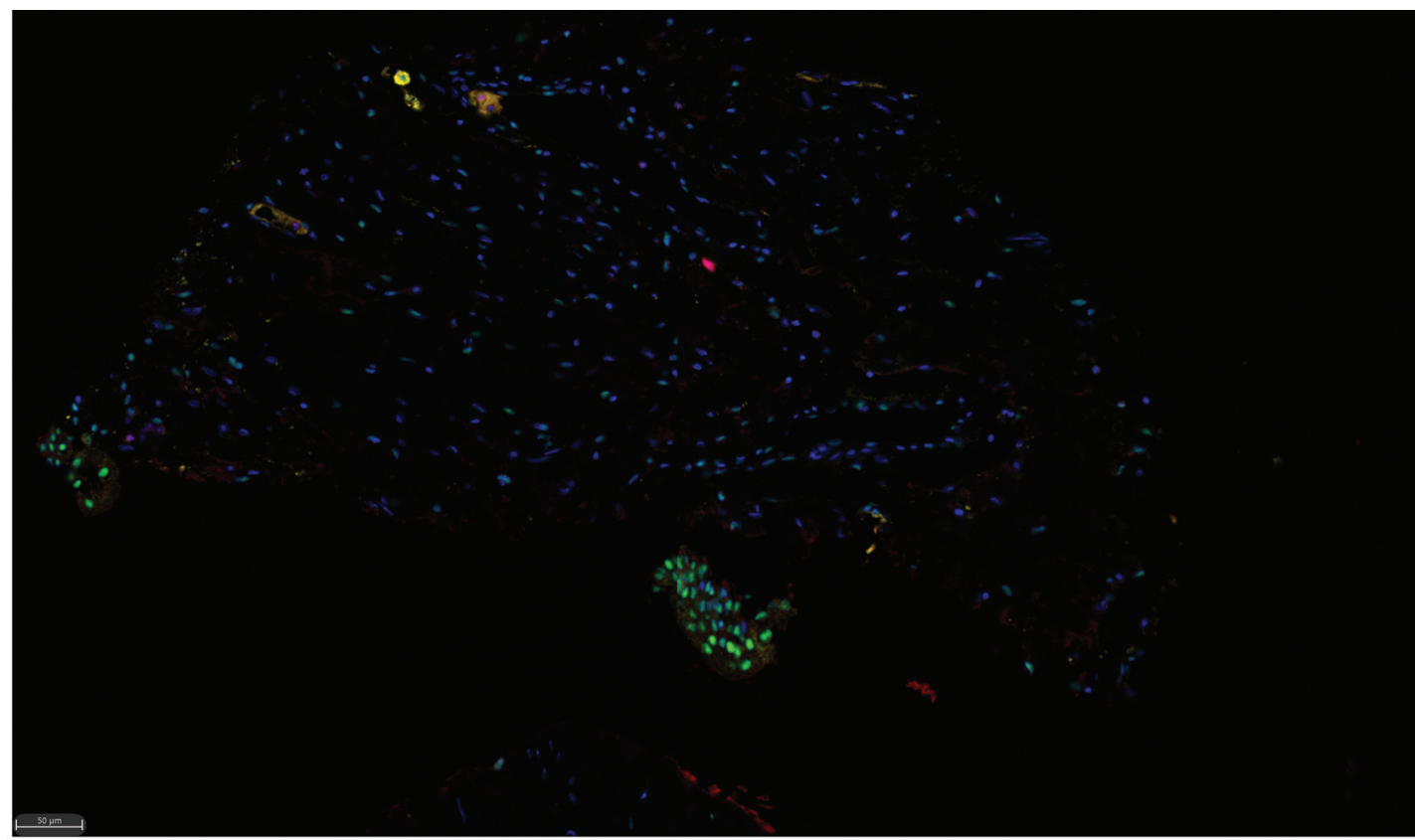

b

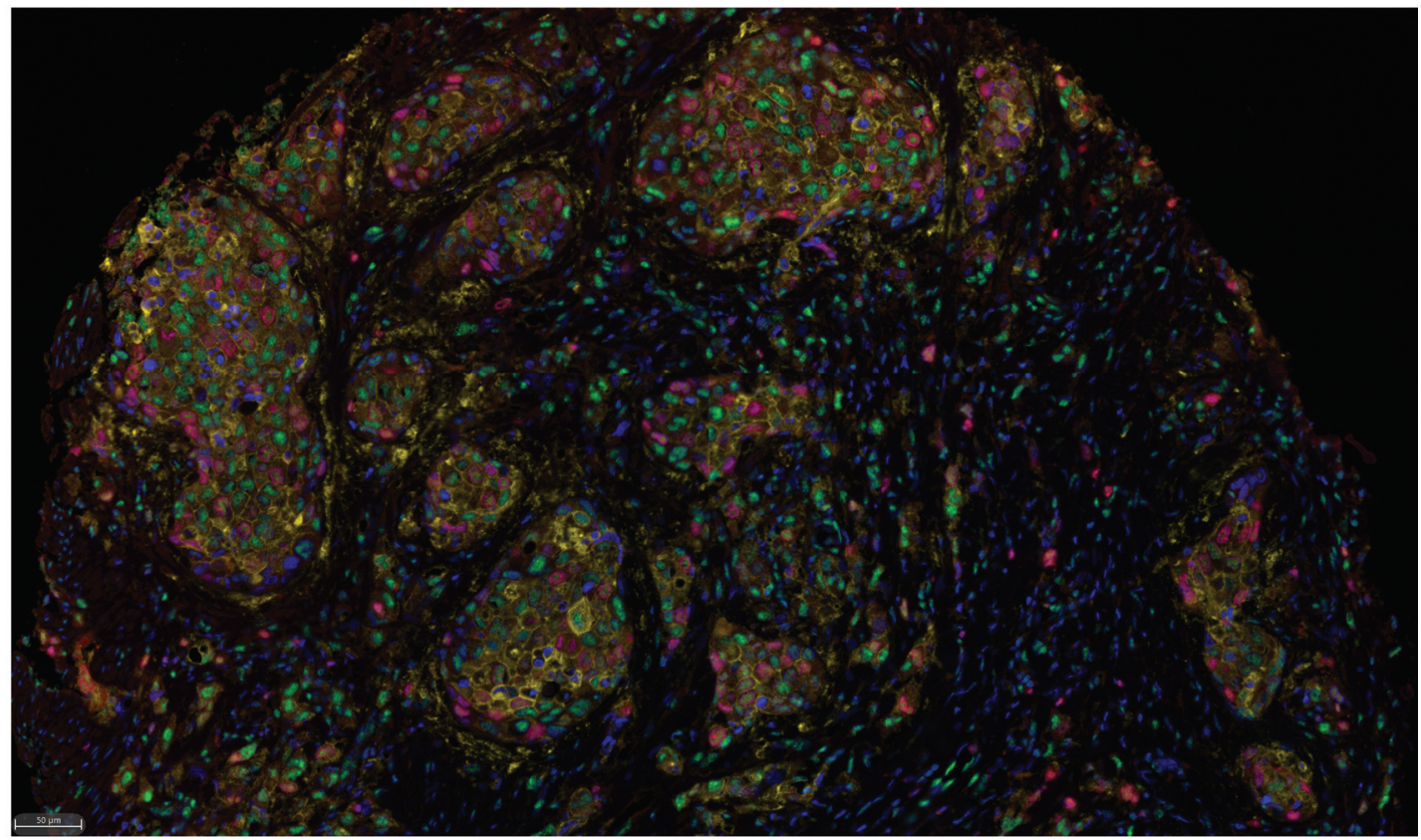

Figure 1. Immunofluorescence of normal tissue (a) and tumor (b) for MRE11 (green), PD-L1 (yellow), and Ki-67 (red) using Vectra 3 scans at 20x magnification. Blue represents DAPI nuclear stain. Note: scale bar represents 50 micrometers.

expression (Table II, Figure 1). On IHC, tumor cells had an increased Ki-67 $\mathrm{H}$ score (33.3 vs. 0, $p<0.001)$ and higher PDL1 H score (6.93 vs. $0, p=0.034)$ and on IF, tumor had increased PD-L1 positive cells (237 vs. 35, $p=0.019)$ and PDL1 positive cell density (274 vs. 53.4 cells $\left./ \mathrm{mm}^{2}, p=0.034\right)$ compared to normal tissue. There were no differences in MRE11 expression between tumor and normal tissue.
Associations with the pattern of recurrence and survival. On student's $t$-test (univariate analysis), three Ki-67 IF measurements, Ki-67 positive cells, percent Ki-67 positive cells, and Ki-67 positive cell density, were associated with a higher likelihood of LOR versus DR $(p=0.036$. $p=0.026$, and $p=0.034$, respectively; Table III). Ki-67 cell density varied by recurrence type: LOR $\left(1,354\right.$ cells $\left./ \mathrm{mm}^{2}\right), \mathrm{DR}$ (557 cells $\left./ \mathrm{mm}^{2}\right)$ and NR 
Table II. Tumor vs. normal tissue values for Ki-67, MRE11, and PD-L1 biomarkers with comparative two-tailed t- tests.

\begin{tabular}{|c|c|c|c|c|}
\hline Molecular variable & Mean for normal & Mean for tumor & Tumor compared to normal & $t$-Test $p$-Value \\
\hline PDL1 H score IHC & 0 & 6.93 & Increased & 0.034 \\
\hline PDL1 CPS IHC $(\#<10, \#>10)$ & $(3,0)$ & $(40,2)$ & No difference & 1.00 \\
\hline Ki67 H score IHC & 0 & 33.3 & Increased & 0.00016 \\
\hline Ki67 percentage IHC $(<1,>1)$ & $(3,0)$ & $(33,9)$ & No difference & 0.88 \\
\hline MRE11 positive cells per $20 \times$ field & 912 & 2319 & Increased & 0.060 \\
\hline$\%$ MRE11 positive cells & 66.2 & 52.8 & Decreased & 0.21 \\
\hline MRE11 positive cell density (cells $/ \mathrm{mm}^{2}$ ) & 1,355 & 2,749 & Increased & 0.17 \\
\hline Ki67 positive cells per $20 \times$ field & 764 & 923 & Increased & 0.84 \\
\hline$\%$ Ki67 positive cells & 39.0 & 22.2 & Decreased & 0.60 \\
\hline Ki67 positive cell density (cells $/ \mathrm{mm}^{2}$ ) & 1,183 & 1,115 & Decreased & 0.96 \\
\hline PD-L1 positive cells per $20 \times$ field & 35 & 237 & Increased & 0.019 \\
\hline$\%$ PD-L1 positive cells & 2.00 & 4.98 & Increased & 0.12 \\
\hline PD-L1 positive cell density (cells/mm²) & 53.4 & 274 & Increased & 0.034 \\
\hline
\end{tabular}

IHC: Immunohistochemistry; CPS: combined positivity score. Significant $p$-values $(p<0.05)$ are shown in bold.

Table III. Two-tailed t-tests for recurrence patterns based on Ki-67, MRE11, and PD-L1 expression.

\begin{tabular}{|c|c|c|c|c|c|c|}
\hline & \multirow[t]{2}{*}{ Mean for NR } & \multirow[t]{2}{*}{ Mean for LOR } & \multirow[t]{2}{*}{ Mean for DR } & \multicolumn{3}{|c|}{$t$-Test $p$-Values } \\
\hline & & & & NR vs. LOR & NR $v s . \mathrm{DR}$ & LOR vs. DR \\
\hline PDL1 H score IHC & 1.22 & 12.5 & 8.63 & 0.14 & 0.39 & 0.72 \\
\hline PDL1 CPS IHC $(\#<10, \#>10)$ & $(17,1)$ & $(13,3)$ & $(7,1)$ & 0.51 & 1.00 & 1.00 \\
\hline Ki67 H score IHC & 30.7 & 43.9 & 17.9 & 0.57 & 0.30 & 0.19 \\
\hline Ki67 percentage IHC $(\#<1, \#>1)$ & $(14,4)$ & $(12,4)$ & $(7,1)$ & 1.00 & 0.97 & 0.86 \\
\hline MRE11 Positive Cells per $20 \times$ field & 2,301 & 2,394 & 2,193 & 0.99 & 0.79 & 0.65 \\
\hline$\%$ MRE11 Positive Cells & 51.3 & 55.1 & 51.2 & 0.80 & 0.99 & 0.70 \\
\hline MRE11 Positive Cell density (cells $/ \mathrm{mm}^{2}$ ) & 2,676 & 2,926 & 2,530 & 0.77 & 0.77 & 0.44 \\
\hline Ki67 Positive Cells per $20 \times$ field & 946 & 1,084 & 489 & 0.74 & 0.069 & 0.036 \\
\hline$\%$ Ki67 Positive Cells & 21.1 & 28.2 & 11.0 & 0.42 & 0.088 & 0.026 \\
\hline Ki67 Positive Cell density (cells $/ \mathrm{mm}^{2}$ ) & 1,111 & 1,354 & 577 & 0.59 & 0.082 & 0.034 \\
\hline PD-L1 Positive Cells per $20 \times$ field & 156 & 345 & 202 & 0.34 & 0.82 & 0.58 \\
\hline$\%$ PD-L1 Positive Cells & 3.10 & 7.11 & 4.92 & 0.28 & 0.72 & 0.71 \\
\hline PD-L1 Positive Cell density (cells $/ \mathrm{mm}^{2}$ ) & 180 & 397 & 231 & 0.34 & 0.83 & 0.58 \\
\hline
\end{tabular}

NR: No recurrence; LOR: local only recurrence; DR: distant recurrence; IHC: immunohistochemistry; CPS: combined positivity score.

$\left(1,111\right.$ cells $\left./ \mathrm{mm}^{2}\right)$. On multivariate Cox proportional hazards model analysis, older age $(\mathrm{HR}=1.08, p=0.015)$, local recurrence (HR=4.14, $p=0.022)$, distant recurrence $(\mathrm{HR}=50.7, p<0.001)$, and positive LVI (HR=5.96, $p=0.015$ ) were associated with worse overall survival. The following were associated with lower recurrence free survival (RFS): age $(\mathrm{HR}=1.09, p=0.016)$, pT3 (HR=8.16, $p<0.001)$, pT4 (HR=1.64, $p=0.004)$, pN2 (HR=4.60, $p=0.009)$, pN3 (HR=7.64, $p=0.010)$, and LVI $(\mathrm{HR}=41.5, p<0.001)$. The only biomarker associated with improved OS was PD-L1 positive cells (HR=1.03, $p=0.036$ ), although it was not associated with RFS.

Developing a molecular signature. Of the 42 pathologic specimens included in this study, one sample was excluded due to unknown margin status bringing the total number of cases included in the PCAs to 41 . We performed a series of PCAs to separate patients by recurrence pattern. The first analysis included all 15 biomarker variables (Figure 2), the second included all 22 clinical and biomarker variables, and the third was limited to margin status and $\mathrm{Ki}-67$ cell density which were significant on UVA. None of the PCAs were successful in distinguishing samples by recurrence pattern.

\section{Discussion}

Local recurrences occur in up to $40 \%$ of patients following definitive management of MIBC and are a significant source of morbidity and mortality (4-6). This pilot study evaluated 
The 15-variable signature on 41 bladder cancer samples

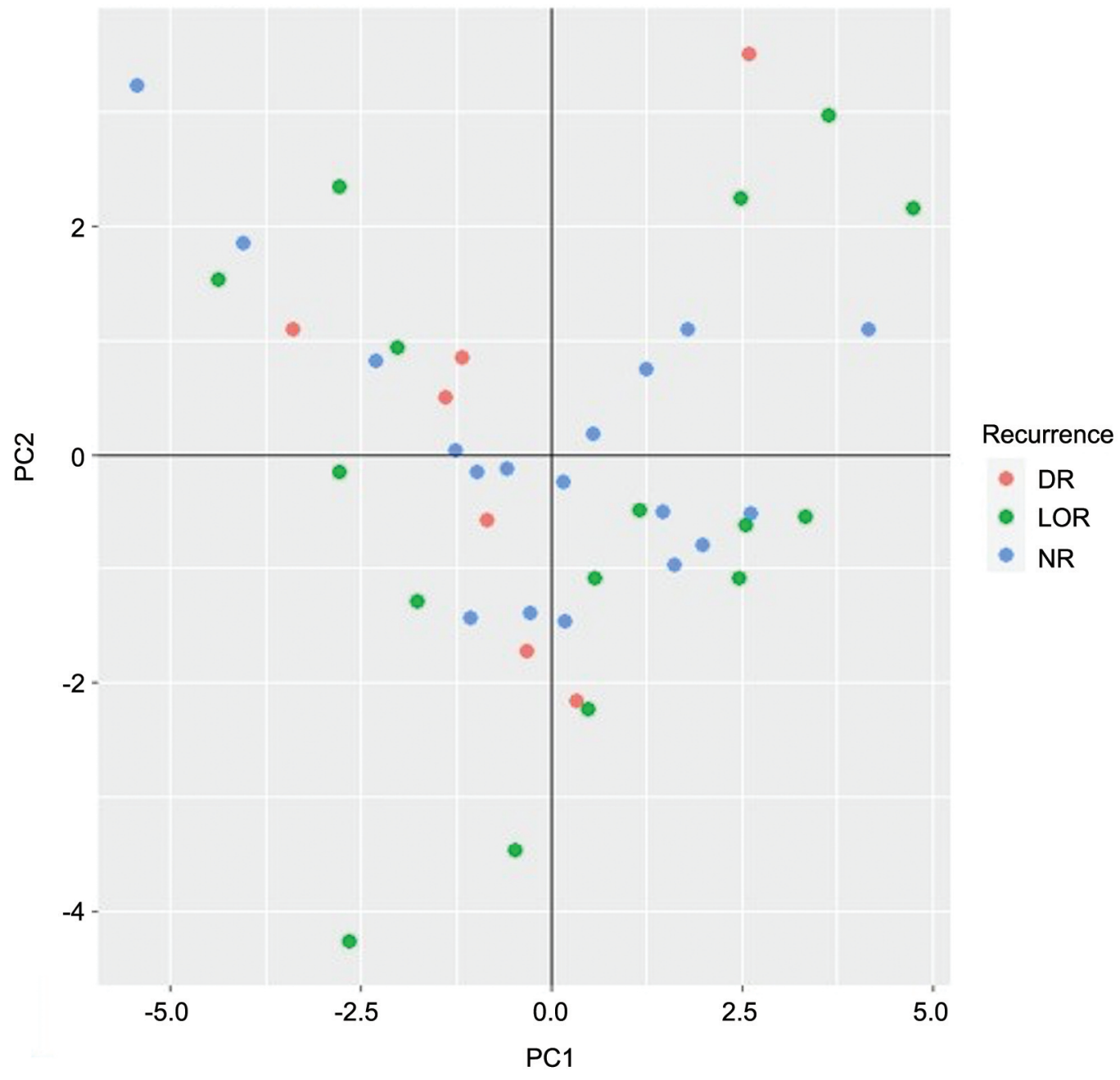

Figure 2. Multidimensional scaling map depicting a principal component analysis (PCA) of all 15 biomarker variables. None of the PCAs used in this study was effective in separating patient samples by recurrence patterns. LOR: Local only recurrence; DR: distant recurrence; NR: no recurrence.

the ability Ki-67, MRE11, and PD-L1 to predict recurrence pattern and inform adjuvant treatment decisions.

Several findings in the current study are worth highlighting. First, we found significant differences in biomarker expression, specifically Ki-67 and PD-L1, which was higher in MIBC tumors compared to surrounding bladder tissue (Table II, Figure 1). These findings are consistent with known hallmarks of cancer including increased cellular proliferation and evasion of immune system detection. Regarding overexpression of PD-L1, this underscores the value of immune checkpoint inhibitor therapy as a treatment modality for bladder cancer. Second, our data show that high Ki-67 cell density may be associated with increased rates of local versus distant recurrence (Table III). Prior work has shown that a high Ki-67 is associated with aggressive disease, recurrence, and cancer-specific survival following cystectomy but not specifically local recurrence $(14-16,20)$. Our data also suggest that tumors with high Ki-67, while associated with higher rates of proliferation, may not necessarily have a tendency to metastasize. Finally, although MRE11 has been previously established as a predictive biomarker in the definitive management of MIBC (14, 21-22), there were no notable findings in the current study regarding MRE11.

This study may lack the statistical power needed to detect a true difference in recurrence patterns based on biomarker expression due to small sample size. Another potential limitation is reliability of IHC and IF techniques which are only semi-quantitative and dependent on many difficult to control 
variables including antibody choice and concentration, fixation technique, and inconsistency in specimen handling, technique, and interpretation. To minimize these errors, we used a highly standardized protocol and automated scoring systems for both IHC and IF. Lastly, the ability to predict recurrence pattern following cystectomy may require more than 3 carefully selected biomarkers. Recent studies have shown that in addition to DNA damage response, proliferative, and PD-1/PDL1 axis biomarkers, molecular subtypes, microRNAs, circulating tumor DNA, and tumor hypoxia modification biomarkers may all be contributing revealing an ever increasingly complex landscape with additional research opportunities (23).

In conclusion, two biomarkers used in this study, Ki-67 and PD-L1 were useful in distinguishing tumor from normal tissue, and high Ki-67 may be associated with LOR. Further work is needed to develop a molecular signature predictive of local recurrence in MIBC following radical cystectomy to guide adjuvant treatment decisions.

\section{Conflicts of Interest}

Dr. Magliocco reports personal fees from Protean BioDiagnostics Inc, outside the submitted work. Dr. Mouw reports grants from Pfizer, personal fees from UpToDate, and personal fees from OncLive, outside the submitted work. Drs. Fossum, Xiong, Daneshmand, Aron, Manojlovic, McCarthy, Phuong, Dorff, Bhanvadia and Ballas have no conflicts of interest to report. All authors agree with being listed as an author. The work has not been published before or being considered for publication elsewhere. There were no human or animal subjects.

\section{Authors' Contributions}

$\mathrm{KB}$, AM, and SD contributed to the conception of the study. YX, MA, ZM, SM and CP performed the study. CCF, LKB, YX and AM contributed to the interpretation and analysis of data. The article was written by CCF, LKB, AM, SD, KWM, TD and SKB. All authors had access to the data.

\section{Acknowledgements}

We would like to acknowledge the Pathology Department at USC for their help with this project. Specifically, Moli Chen and Emyli Clark for help with TMA production. Additionally, we were helped by the Advanced Analytical and Digital Pathology lab within the Pathology Department at Moffitt Cancer Center for their work on this project. Specifically, we would like to thank Neale LopezBlanco and Carlos Moran Segura for tissue preparation and staining, Carlos Moran Segura for antibody panel design and multi-spectra scanning, Jonathan Nguyen for image quantification within HALO, and Dr. Daryoush Saeed-Vafa for directing the laboratory.

\section{References}

1 Siegel RL, Miller KD and Jemal A: Cancer statistics, 2020. CA Cancer J Clin 70(1): 7-30, 2020. PMID: 31912902. DOI: $10.3322 /$ caac. 21590
2 Gray PJ, Fedewa SA, Shipley WU, Efstathiou JA, Lin CC, Zietman AL and Virgo KS: Use of potentially curative therapies for muscle-invasive bladder cancer in the United States: results from the National Cancer Data Base. Eur Urol 63(5): 823-829, 2013. PMID: 23200811. DOI: 10.1016/j.eururo.2012.11.015

3 Grossman HB, Natale RB, Tangen CM, Speights VO, Vogelzang NJ, Trump DL, deVere White RW, Sarosdy MF, Wood DP Jr, Raghavan D and Crawford ED: Neoadjuvant chemotherapy plus cystectomy compared with cystectomy alone for locally advanced bladder cancer. N Engl J Med 349(9): 859-866, 2003. PMID: 12944571. DOI: 10.1056/NEJMoa022148

4 Christodouleas JP, Hwang WT and Baumann BC: Adjuvant radiation for locally advanced bladder cancer? A question worth asking. Int J Radiat Oncol Biol Phys 94(5): 1040-1042, 2016. PMID: 27026310. DOI: 10.1016/j.ijrobp.2016.01.015

5 Baumann BC, Guzzo TJ, He J, Vaughn DJ, Keefe SM, Vapiwala N, Deville C, Bekelman JE, Tucker K, Hwang WT, Malkowicz SB and Christodouleas JP: Bladder cancer patterns of pelvic failure: implications for adjuvant radiation therapy. Int J Radiat Oncol Biol Phys 85(2): 363-369, 2013. PMID: 22658217. DOI: 10.1016/j.ijrobp.2012.03.061

6 Reddy AV, Pariser JJ, Pearce SM, Weichselbaum RR, Smith ND, Steinberg GD and Liauw SL: Patterns of failure after radical cystectomy for pT3-4 bladder cancer: Implications for adjuvant radiation therapy. Int J Radiat Oncol Biol Phys 94(5): 1031-1039, 2016. PMID: 27026309. DOI: 10.1016/j.ijrobp.2015.10.051

7 Kamoun A, de Reyniès A, Allory Y, Sjödahl G, Robertson AG, Seiler R, Hoadley KA, Groeneveld CS, Al-Ahmadie H, Choi W, Castro MAA, Fontugne J, Eriksson P, Mo Q, Kardos J, Zlotta A, Hartmann A, Dinney CP, Bellmunt J, Powles T, Malats N, Chan KS, Kim WY, McConkey DJ, Black PC, Dyrskjøt L, Höglund M, Lerner SP, Real FX, Radvanyi F and Bladder Cancer Molecular Taxonomy Group: A consensus molecular classification of muscle-invasive bladder cancer. Eur Urol 77(4): 420-433, 2020. PMID: 31563503. DOI: 10.1016/j.eururo.2019.09.006

8 Shariat SF, Chromecki TF, Cha EK, Karakiewicz PI, Sun M, Fradet Y, Isbarn H, Scherr DS, Bastian PJ, Pummer K, Fajkovic H, Sagalowsky AI, Ashfaq R, Doblinger M, Cote RJ and Lotan Y: Risk stratification of organ confined bladder cancer after radical cystectomy using cell cycle related biomarkers. J Urol 187(2): 457462, 2012. PMID: 22177145. DOI: 10.1016/j.juro.2011.10.031

9 Lotan Y, Bagrodia A, Passoni N, Rachakonda V, Kapur P, Arriaga Y, Bolenz C, Margulis V, Raj GV, Sagalowsky AI and Shariat SF: Prospective evaluation of a molecular marker panel for prediction of recurrence and cancer-specific survival after radical cystectomy. Eur Urol 64(3): 465-471, 2013. PMID: 23571005. DOI: $10.1016 /$ j.eururo.2013.03.043

10 Mitin T and Choudhury A: The role of biomarkers in bladder preservation management of muscle-invasive bladder cancer. World J Urol 37(9): 1767-1772, 2019. PMID: 30218307. DOI: 10.1007/s00345-018-2480-7

11 Mitra AP, Lam LL, Ghadessi M, Erho N, Vergara IA, Alshalalfa M, Buerki C, Haddad Z, Sierocinski T, Triche TJ, Skinner EC, Davicioni E, Daneshmand S and Black PC: Discovery and validation of novel expression signature for postcystectomy recurrence in high-risk bladder cancer. J Natl Cancer Inst 106(11): dju290, 2014. PMID: 25344601. DOI: 10.1093/jnci/dju290

12 Choi W, Porten S, Kim S, Willis D, Plimack ER, HoffmanCensits J, Roth B, Cheng T, Tran M, Lee IL, Melquist J, Bondaruk J, Majewski T, Zhang S, Pretzsch S, Baggerly K, 
Siefker-Radtke A, Czerniak B, Dinney CP and McConkey DJ: Identification of distinct basal and luminal subtypes of muscleinvasive bladder cancer with different sensitivities to frontline chemotherapy. Cancer Cell 25(2): 152-165, 2014. PMID: 24525232. DOI: 10.1016/j.ccr.2014.01.009

13 Seiler R, Ashab HAD, Erho N, van Rhijn BWG, Winters B, Douglas J, Van Kessel KE, Fransen van de Putte EE, Sommerlad M, Wang NQ, Choeurng V, Gibb EA, Palmer-Aronsten B, Lam LL, Buerki C, Davicioni E, Sjödahl G, Kardos J, Hoadley KA, Lerner SP, McConkey DJ, Choi W, Kim WY, Kiss B, Thalmann GN, Todenhöfer T, Crabb SJ, North S, Zwarthoff EC, Boormans JL, Wright J, Dall'Era M, van der Heijden MS and Black PC: Impact of molecular subtypes in muscle-invasive bladder cancer on predicting response and survival after neoadjuvant chemotherapy. Eur Urol 72(4): 544-554, 2017. PMID: 28390739. DOI: 10.1016/j.eururo.2017.03.030

14 Miyamoto DT, Mouw KW, Feng FY, Shipley WU and Efstathiou JA: Molecular biomarkers in bladder preservation therapy for muscle-invasive bladder cancer. Lancet Oncol 19(12): e683-e695, 2018. PMID: 30507435. DOI: 10.1016/S1470-2045(18)30693-4

15 Tanabe K, Yoshida S, Koga F, Inoue M, Kobayashi S, Ishioka J, Tamura T, Sugawara E, Saito K, Akashi T, Fujii Y and Kihara K: High Ki-67 expression predicts favorable survival in muscleinvasive bladder cancer patients treated with chemoradiation-based bladder-sparing protocol. Clin Genitourin Cancer 13(4): e243-e251, 2015. PMID: 25936588. DOI: 10.1016/j.clgc.2015.03.002

16 Rödel C, Grabenbauer GG, Rödel F, Birkenhake S, Kühn R, Martus P, Zörcher T, Fürsich D, Papadopoulos T, Dunst J, Schrott KM and Sauer R: Apoptosis, p53, bcl-2, and Ki-67 in invasive bladder carcinoma: possible predictors for response to radiochemotherapy and successful bladder preservation. Int $\mathrm{J}$ Radiat Oncol Biol Phys 46(5): 1213-1221, 2000. PMID: 10725634. DOI: 10.1016/s0360-3016(99)00544-1

17 Parra ER, Uraoka N, Jiang M, Cook P, Gibbons D, Forget MA, Bernatchez C, Haymaker C, Wistuba II and Rodriguez-Canales $\mathrm{J}$ : Validation of multiplex immunofluorescence panels using multispectral microscopy for immune-profiling of formalin-fixed and paraffin-embedded human tumor tissues. Sci Rep 7(1): 13380, 2017. PMID: 29042640. DOI: 10.1038/s41598-01713942-8

18 Miles GJ, Powley I, Mohammed S, Howells L, Pringle JH, Hammonds T, MacFarlane $\mathrm{M}$ and Pritchard C: Evaluating and comparing immunostaining and computational methods for spatial profiling of drug response in patient-derived explants. Lab Invest 101(3): 396-407, 2021. PMID: 33318618. DOI: $10.1038 / \mathrm{s} 41374-020-00511-3$
19 Brandt S, Samartzis EP, Zimmermann AK, Fink D, Moch H, Noske A and Dedes KJ: Lack of MRE11-RAD50-NBS1 (MRN) complex detection occurs frequently in low-grade epithelial ovarian cancer. BMC Cancer 17(1): 44, 2017. PMID: 28073364. DOI: $10.1186 / \mathrm{s} 12885-016-3026-2$

20 Margulis V, Lotan Y, Karakiewicz PI, Fradet Y, Ashfaq R, Capitanio U, Montorsi F, Bastian PJ, Nielsen ME, Müller SC, Rigaud J, Heukamp LC, Netto G, Lerner SP, Sagalowsky AI and Shariat SF: Multi-institutional validation of the predictive value of Ki-67 labeling index in patients with urinary bladder cancer. J Natl Cancer Inst 101(2): 114-119, 2009. PMID: 19141773. DOI: $10.1093 /$ jnci/djn451

21 Choudhury A, Nelson LD, Teo MT, Chilka S, Bhattarai S, Johnston CF, Elliott F, Lowery J, Taylor CF, Churchman M, Bentley J, Knowles MA, Harnden P, Bristow RG, Bishop DT and Kiltie AE: MRE11 expression is predictive of cause-specific survival following radical radiotherapy for muscle-invasive bladder cancer. Cancer Res 70(18): 7017-7026, 2010. PMID: 20843819. DOI: 10.1158/0008-5472.CAN-10-1202

22 Laurberg JR, Brems-Eskildsen AS, Nordentoft I, Fristrup N, Schepeler T, Ulhøi BP, Agerbaek M, Hartmann A, Bertz S, Wittlinger M, Fietkau R, Rödel C, Borre M, Jensen JB, Orntoft $\mathrm{T}$ and Dyrskjøt L: Expression of TIP60 (tat-interactive protein) and MRE11 (meiotic recombination 11 homolog) predict treatment-specific outcome of localised invasive bladder cancer. BJU Int 110(11 Pt C): E1228-E1236, 2012. PMID: 23046361. DOI: $10.1111 /$ j.1464-410X.2012.11564.X

23 Solanki AA, Venkatesulu BP and Efstathiou JA: Will the use of biomarkers improve bladder cancer radiotherapy delivery? Clin Oncol (R Coll Radiol) 33(6): e264-e273, 2021. PMID: 33867226. DOI: 10.1016/j.clon.2021.03.017
Received April 20, 2021

Revised June 22, 2021

Accepted July 5, 2021 